\title{
Japan's new media art development enlightenment to promote traditional arts in Heilongjiang province
}

\author{
Hongfang Duan, Lei Tian \\ Heilongjiang University of Technology, Jixi, Heilongjiang, 158100
}

Keywords: Japan's new media art; Development; Traditional art; revelation

\begin{abstract}
The information age today, the development of new media has become the mainstream in the development of The Times. New media for the development of traditional art has a certain impact, but also have very good from each other and use between, formed the new media art, and Japan are ahead in the world in the field of new media art. For the development of new media art even in the traditional art in China has played a certain reference function. This article will with the present situation of the traditional art in Heilongjiang province, discusses the Japanese new media art development enlightenment to the development of Chinese traditional art.

New media technology in today's society an unprecedented development, become the mainstream of society. By winning it village of new media art forms with the development of science and technology is becoming more and more rich.The most obvious feature of the new media art is to make the art appreciation into a more three-dimensional, real effect, and can process of interaction.This way compared with traditional art appreciation ways quite single more attractive, thus in the speed of the ear development and spread around the world.And in the impact of the development of our traditional culture constantly. But we all know, traditional culture is a continuation of our national history, culture, embodies the we each national unique ideological and moral, aesthetic style and temperament mind, way of thinking and language, has penetrated in our bones, flowing in our blood, is the symbol of the Chinese national spirit civilization.So, we can not forgetting, needs us to carry forward traditional culture, but we can't afford to conform to the trend of the development of the era, how to combine the new media and traditional culture of organic, use of new media art, make the traditional culture, enrich the content of the new media of cash is worth thinking and discussion questions.
\end{abstract}

\section{Japan's new media art development process}

Since the 21st century, media art as a new trend. It is important that accompanied by a personal computer running speed increase and the network environment to optimize and ushered in the era of multi-media. The audience is no longer just viewing, but can step in works of art, also known as experience, participated in the art. The research of virtual reality technique to create artificial reality, and the research progress of artificial life science of living systems, and media art from overseas to enter Japan. Although new media art in Europe as the center, but the Japanese artist to extend this possibility is extremely rich artistic form out another style. Their works with distinct cultural characteristics in Japan, on the basis of this, and spawned many new ways.

Japan's new media art started after the second world war. Began to appear in the $1950 \mathrm{~s}$ to absorb new technology performance of music, art, literature, drama, such as group, one of the most important is "experiment workshops" activity. It is built on modern poet Long mouth for organizers brought together from a variety of different areas of 14 young avant-garde artists and comprehensive art group. The experimental workshops activity lasted from 1951 to 1951.SONY in 1953, they borrow the predecessor of the Tokyo communication industry's latest development of automatic tape recorders and projectors, in the slide show at the same time, play the electronic music; Hosted the 1956 tape music (electronic) music and automatic slide audition. Experimental workshops that will surely make them become a pioneer of post-war Japanese avant-garde art 
movement. In the $1960 \mathrm{~s}$, from the Japanese economic high growth of the late start, as a kind of new media art trend. In 1970, reached its climax at Osaka.

The Osaka world expo for the late $60 \mathrm{~s}$ thought and methodology of modern art provides a practical stage, is the collection of Japanese modern art dacheng, so to speak.Design, architecture, sculpture, video, music, and other fields of artists to participate in the international event design and production activities. The turning point of Osaka, Japan's postwar modern art expo.

Since the $1990 \mathrm{~s}$, with the popularization of Internet technology, the "virtual" and "reality" dialogue again triggered intense response Japanese artist.They are living in a material relative abundance of consumption society, the consumer society is also represented by computer, digital technology, biological technology of science and technology by leaps and bounds. With TV, cartoon, pictures and video and the generation of growth, in the artistic creation, choosing the most familiar way and means.Medium heat, image widened them to engage in artistic creation, expand the space of the spiritual life, also make the diversity of artistic creation and personality development, at the same time more is a kind of MinZuShi spiritual experience.

During this time, the most representative artists is starting from the mid - 1980 - s using diode electronic counter palace island of male production device, electronic music TianLiangsi leading figures in the pool, from the "goddess" of science and technology to the guardians "natural" senmarikomori, etc. They are the combination of traditional Japanese culture at the same time, the maximum play to the science and technology brings the new art form of cash.Collection in the text, graphics, images, animation, video, video, sound, music and other traditional media advantages, combined with the function of computer interaction, through meticulous planning idea, combined with a variety of expression, audience, attracted a lot of culture guides the public's aesthetic concept to digital transformation.Above we can see, a short span of time, Japan's new media art has developed into the mainstream of the new media art world. New media art of traditional art, along with the development of science and technology will be break down the traditional art space. At present, the development of the new media of interactivity is more than the other forms of art, it is a innovation.

\section{Heilongjiang province present situation analysis in traditional art}

Under the impact of the new media and traditional media is momentum, gradually faded. Strong into the development of new media art caused great impact for the traditional art.The new media art of China is still in the initial stage of development, traditional arts are still breathing space. But in the process of the development of new media art, short decades time, new media art has become the mainstream of today art, popular and respected.Thus can foresee the development trend of China's new media art, certainly will also is on a roll, developing rapidly. The traditional art, is clearly a major crisis.

We first analyze the situation of the development of traditional art, with the development of traditional art in Heilongjiang province as an example analysis. China's vast territory, many nationalities, present different aesthetic orientation, different regional of the traditional regional art treasure of the Chinese nation.Heilongjiang regional traditional art constitutes an integral part of the whole Chinese nation's culture, to made a kind of unique scenery in Heilongjiang province, Heilongjiang province traditional art forms mainly include the following aspects: baishanblackwaterhezhen nationality in culture and art, culture and art, Mr\&matrimonial art, birch bark, skill and clipart.At present the traditional art faces enormous survival crisis.One is very many traditional art lacks successors, many senior entertainers already left the world, grasping certain, the high-level technical person changed professions in abundance, the young person to the artware value knew insufficiently was not willing to study, to caused the traditional process faced with the danger which was lost.In a word, the improvement of cultural quality of the whole, for the long-term development of the industry, is very important.

The second is the lack of protection of traditional arts and the rank of the specialized agencies, the necessary funds. The majority of traditional arts also did not have a specialized institutions for the protection or protection of persons, protection work hard to guarantee.The lack of funds, is also 
the current protection of the traditional arts face a prominent problem. Traditional art institutions and team set up, protect precious traditional art information needed for the hardware facilities, as well as the retrieval and development work, etc., all need certain funds.At present, since there is no special fund, and difficult.

The third is the traditional art and the contradictions of the modern market economy.The existence of traditional arts and development in an era of a specific environment, due to traditional arts with modern material life changes and the shock of the market economy, it will inevitably lead to some of the traditional arts and the contraction or even death.The contradiction of traditional crafts and modern market economy, make the development of traditional art has entered a period of very serious.So, in such a severe situation, how to promote and develop the traditional art is a problem we should think carefully.

\section{How to develop traditional off in the form of new media art}

New media art for creation of artists' art provides a new direction, they can through new media to express their artistic conception with good, this will than traditional art to attract eyeball.New Media Communication swift, large amounts of information, has attracted people's attention. The integrated use of new media for artistic creation is an inevitable trend, but this does not mean that traditional arts are replaced.The most obvious feature of the new media art is comprehensive and inclusive. In this new era, the emergence of new media art provides more possibilities for the traditional art expression.New media art cannot leave the culture, but also inseparable from the tradition, even more to the spirit of the local ethnic culture. Traditional folk art is the foundation of new media art and new media art is the sublimation of traditional folk art and continue.

The evolution of Chinese traditional culture after one thousand enduring, extensive and profound, connotation is rich, has a strong vitality, is still deeply influenced the Chinese nation.However, this has been passed down from one thousand precious traditional art, experiencing severe tests. In this form, we must give full play to the advantages of modern media technology, strengthen the refining and transmission of traditional culture essence, create the best products in national culture.Perhaps, as Japan's new media art development rapidly, still cannot leave for its local thrift and inheritance of traditional culture.We wish to consolidate legacy media language and cultural spirit, let the world to become more aware of China at present and in the past, thus achieving a cultural heritage for a national arts boutique.

The development of new media art has a dual role in the development of the traditional culture, brings the opportunity, at the same time also brought challenges.Both inherited and developed the traditional arts, on the other hand also in denial and reform the traditional art.Traditional arts come from life and higher than life forms, is the real life is reflected or sublimation and refining.However, from the date of the birth of new media art is the mirror of the use of high-tech technology to network virtual world, show us is dazzling virtual reality.Such technology is difficult to traditional performance art, because it is not suitable for our country's traditional culture, especially as many areas such as Heilongjiang regional national special cultural manifestation of the development process and cultural symbols.It is difficult to perfect the performance of traditional culture and arts at the special flavor. In addition, traditional arts have been out of authoritative position, and is subject to the dissemination of the culture of unilateral output; and the number of new media art is a high degree of autonomy and the culture that is equal participation in culture, emphasized the interactive. Old and new, two forms of culture in the development of interaction and antagonism and conflict is inevitable.

The boundaries between culture, however, is not so clear and do not break, cultural blend between the phenomenon is very common, art forms can even across time, race.No matter what kind of cultural form, is part of the human material civilization and spiritual civilization. This is the most essential feature of the culture.New media art is still belongs to the category of culture.In common with culture, it is this common makes between different forms of culture can learn from each other, to absorb the other side of the reasonable factors, forming a contains two kinds of art connotation of the new culture,Therefore, new media art and the traditional culture should use the 
opportunity which each time may exchange and collide, profits from the bilateral outstanding connotation and the special characteristic mutually, finally forms both contains the external culture and to have the bright native place characteristic new cultural art shape.

As we all know, national is the world. The output of culture must have the characteristics of this nation. In this respect is worth our using for reference in Japan, Japanese anime culture has been exported to all over the world, Japan to become the world's famous animation power. The cartoon form rich content, and mostly reflect the traditional culture. With the spread of new media art forms its own traditional culture and remarkable achievements worth our using for reference.

So in the process of cultural transmission, need of a new form of transmission of new media art, it breaks the limitation of time and space, which is based on the network openness and richness, but also for the spread of traditional culture and the research provides an unprecedented convenience. As you can see, the traditional culture in the implementation of network platform for broader the spread and development of China's traditional culture offers new possibilities and broad space for development.

In short, the development of new media art represented by Japan and represented by the traditional culture in Heilongjiang province of contradiction between the development of Chinese traditional culture, but also is not irreconcilable, between the two is mutual influence and reference. In order to promote mutual growth.

\section{Reference}

[1] The inspiration of Chinese traditional way of thinking on new media art design [J]. Journal of fine arts, 2016, (05) : 123-127.

[2] Wang xinfeng.Very China in new media design [D].Dalian university of technology, 2013.

[3] Wang xuan.The integration of science and art [D]. Henan university, 2008. 